\title{
From Cooperation to Conflict? Swedish Rehabilitation Professionals' Experiences of Interorganizational Cooperation.
}

\author{
Christian Ståhl, Tommy Svensson and Kerstin Ekberg
}

\section{Linköping University Post Print}

N.B.: When citing this work, cite the original article.

The original publication is available at www.springerlink.com:

Christian Ståhl, Tommy Svensson and Kerstin Ekberg, From Cooperation to Conflict? Swedish Rehabilitation Professionals' Experiences of Interorganizational Cooperation., 2011, Journal of occupational rehabilitation, (21), 3, 441-448.

http://dx.doi.org/10.1007/s10926-010-9281-1

Copyright: Springer Verlag (Germany) http://www.springerlink.com/

Postprint available at: Linköping University Electronic Press http://urn.kb.se/resolve?urn=urn:nbn:se:liu:diva-66499 


\section{From cooperation to conflict? Swedish rehabilitation professionals' experiences of interorganizational cooperation}

Christian Ståhl ${ }^{1,2}$, Tommy Svensson ${ }^{1,3,4}$, Kerstin Ekberg ${ }^{1,2}$

${ }^{1}$ National Centre for Work and Rehabilitation, Department of Medical and Health Sciences, Linköping University, Linköping, Sweden

${ }^{2}$ HELIX VINN Excellence Centre, Linköping University, Linköping, Sweden

${ }^{3}$ Department of Behavioural Sciences and Learning, Division of Sociology, Linköping

University, Linköping, Sweden

${ }^{4}$ Nordic School of Public Health, Göteborg, Sweden

Corresponding author: Christian Ståhl, National Centre for Work and Rehabilitation,

Department of Medical and Health Sciences, Linköping University, 58183 Linköping,

Sweden. E-mail: christian.stahl@liu.se 


\section{Abstract}

\section{Purpose}

This article analyses Swedish rehabilitation professionals' experiences of interorganizational cooperation in return-to-work and labour market reintegration.

\section{Method}

Two groups $(n=15)$ from different organizations met on a regular basis to discuss their practice from a cooperation perspective. The participants had experience of cooperation in the organizational setting of Coordination Associations (CAs). The groups worked with a tutor according to a problem-based methodology, to discuss how their practice is influenced by new structures for cooperation. The material was analysed inductively using qualitative content analysis.

\section{Results}

Interorganizational cooperation in rehabilitation is generally perceived as promoting coherence and communication. Nevertheless, there are several contradictory factors in the implementation of such work forms, primarily inflexible sickness insurance regulations and inability of managers to implement cooperation in regular practice.

\section{Conclusions}

While interorganizational cooperation promotes professional discretion and tailored solutions, the insurance system contradicts such ambitions through increased governance. Ultimately, the contradictory tendencies of cooperative initiatives and the stricter governance of sickness insurance regulations are political matters. If political attempts to promote interorganizational cooperation are to succeed, the increasing sectorization that results from strict governance of sickness insurance regulations needs to be targeted on a system level. 


\section{Introduction}

Interorganizational cooperation in rehabilitation and return-to-work has gained increasing attention in the last decade [1-8], and a research agenda towards improving cooperation and communication between return-to-work actors has been suggested [9]. Research on cooperation in rehabilitation and return-to-work has focused on disability managers and return-to-work coordinators as facilitators or intermediaries between actors [10-12], but politically driven attempts toward structural or interorganizational interventions have received less attention. Some studies have focused on how the different interests, policies and working methods of different actors may be coordinated. Obstacles to such ambitions have been identified, such as conflicting organizational priorities [7], lack of interorganizational trust and failure to communicate $[6,8]$.

A Swedish initiative for improving interorganizational cooperation in the rehabilitation field is the formation of Coordination Associations (CAs). These CAs are based on a legislated structure for political and financial coordination and interorganizational cooperation in rehabilitation, return-to-work and labour market reintegration. This cooperation involves healthcare, social insurance, social services and employment services.

The aim of this article is to describe and analyse the experiences of Swedish rehabilitation professionals engaged in CAs. The article focuses on how the professionals have experienced the development of cooperation through this structure, and how cooperative work forms relate to regular practice in the organizations. 
In the Swedish sickness insurance system, the responsibility for rehabilitation and return-towork is to a large extent a matter for public organizations. Apart from employers' financial responsibility for the first two weeks of sick leave and for workplace accommodations, most of the rehabilitation process is planned and executed within the public system (see Table 1).

[Table 1 about here.]

As the sick-listing process is divided among several actors, it is important that there is good cooperation between them. Since the 1990s, the Swedish government has invested in developing different structures to improve cooperation within the public system for rehabilitation, return-to-work and labour market reintegration. In 2004, permanent legislation on cooperation was introduced: the Financial Coordination of Rehabilitation Measures Act (FINSAM), which is the most structured form of interorganizational cooperation yet enacted. In the legislation, it is stated that financial coordination can be carried out through the formation of Coordination Associations (CAs), with municipalities, healthcare services, the Swedish Social Insurance Agency and the Public Employment Service as participating organizations. According to FINSAM, CAs are to operate at a local municipal level by using a joint budget to target people in need of coordinated rehabilitation from more than one of the participating organizations, for example, the long-term sick, disabled or unemployed. The task of the CAs is to facilitate return-to-work and devise the most cost-effective use of available resources. Every CA has a local political board and an office with a coordinator. Although the CAs are involved in financial coordination, in practice they may be more involved in 
cooperation, for example, through interorganizational work forms. (For a useful conceptualization of the concepts of cooperation, collaboration and coordination, see [13].)

One cooperation initiative that was subsequently transformed into a CA has been reviewed by the European Commission [14]. The reviewers identified it as an innovative example of good practice in the rehabilitation field, concluding that it is in line with the labour market strategy of the European Union in its emphasis on facilitating access to active labour market measures [15]. However, a few points of concern regarding the transferability of the practice to other national contexts, were identified in the review, e.g. the lack of employer involvement. Cooperation in the CAs is carried out between public welfare services; the engagement of employers in facilitating return-to-work is not emphasized [14]. Studies of organizational interests in similar cooperative structures also conclude that self-interest and low trust threaten to spoil cooperative initiatives, which suggests that a legislated structure is not enough to make cooperation work in practice $[8,16,17]$.

In 2008, the Swedish government introduced new sickness insurance regulations, involving a time schedule for rehabilitation and return-to-work. Before the changes, there were no set time limits in the system. According to the new regulations, the work ability of the sick-listed worker's is assessed in relation to his/her present work task up to the $90^{\text {th }}$ day of sickness absence. Thereafter (up to day 180) the assessment is made in relation to other work tasks with the same employer, and after 180 days, in relation to the labour market at large. The new time schedule has changed the conditions for sick-listing, in particular regarding work ability assessments. A more narrow time perspective puts higher demands of purposeful cooperation between relevant actors in the processes of rehabilitation and return-to-work. 


\section{Methods}

This is an explorative study of the experiences of Swedish rehabilitation professionals from different public organizations. To facilitate an analysis of such issues, an interpretative approach was called for, and qualitative methods for data collection were used [18].

\section{Participants in the study}

Two groups of officials from the Social Insurance Agency, the Public Employment Service, primary healthcare and municipal rehabilitation services met on a regular basis to discuss how changes in policy affected their practice. The groups were located in two different municipalities in eastern Sweden. The selection of participants was made through discussions with coordinators in two CAs, the criteria for inclusion being that all the relevant public actors in rehabilitation and return-to-work should be represented, and that all participants had experience of everyday work with clients. All participants were female, and the age distribution was broad, with participants from their twenties to their sixties. All participants had worked in the field of rehabilitation and/or return-to-work for more than three years. They were all informed about the purpose of the study and gave their consent to participation and to the audio recordings of the meetings. The organizational backgrounds of the participants are presented in Table 2 .

[Table 2 about here.] 
The groups met for approximately two hours on seven occasions each, with the first meeting extended by one hour to introduce the participants to the study and to the principles of problem-based learning $[19,20]$. Problem-based learning was used as a pedagogical tool to structure the meetings; the educational goal for the participants was to use the group meeting as a forum to improve their cooperative strategies across organizational borders. A tutor was assigned to the groups to help them structure the meetings and to function as a facilitator in the discussions. One researcher also attended the group meetings, primarily as an observer but at some points also as a resource person with regard to research in the rehabilitation field.

There were several reasons for the use of problem-based learning. Firstly, this was done in order to give the participants a purpose for the meetings; the idea was that they would benefit from meeting and working with other professionals in a structured way. Using problem-based learning as a method for professional development contributes to illuminating and systematizing informal and tacit knowledge [21].

As a research method, problem-based group meetings result in a rich material that is open for analyses on several levels from different disciplinary perspectives. Compared with focus groups or group interviews, this method provides less static and more in-depth knowledge of the participants' reality. Further, the approach enables them to acquire practical knowledge from taking part in the study [22].

In problem-based learning, different forms of material may work as an input or a starting point to discussions. At the first meeting, the participants chose from a selection of newspaper articles selected by the first author about recent changes in the Swedish sickness insurance system to provide such input. At subsequent meetings, no such starting points were introduced; instead, the groups were asked to end each meeting by posing a question for 
discussion at the next meeting. The discussions evolved into covering a multitude of topics, such as: consequences of policy changes; the relationship between sickness insurance and labour market policies; participants' working conditions and relationship with managers; and cooperation within and between organizations. For this article, the development of cooperation through the CAs was chosen as the theme for analysis.

The groups met from February to May 2009. All group meetings were documented in several ways: meetings were recorded and transcribed verbatim; notes were taken by both the participants and the researcher, both during and after the meetings; whiteboards were used during meetings, and then photographed and sent out to the groups; each group member was also given a notebook for their personal reflections, and on some occasions these were used as input for discussions.

The analysis was guided by the principles of a qualitative content analysis [18]. The transcribed material was read through several times and compared with notes to get an overall view of the content. Organizing the material into categories or themes is a way of making sense of the data, and a process in which research questions are constantly formulated and redefined, in order to guide the coding of the transcripts [23].

Since the study involves a rich material, a broad variety of issues was covered with several possible paths for analysis. The first step was thus to make a preliminary categorization of recurrent issues in the material [i.e. open coding, 23]. This was done manually by the first author, using highlighters in different colours, and cutting and pasting. The comprehensive documentation (the researcher's and participants' notes, photographs of whiteboards etc.) facilitated the reading of the lengthy transcripts from the group meetings and was used to form questions to guide the categorization. 
After producing an initial suggestion for categorization, this was presented to the coauthors for discussion. Then the process continued until agreement was reached on a thematic structure that was well grounded in the empirical material and showed satisfactory internal homogeneity and external heterogeneity, i.e. well-defined themes that do not overlap [18]. After this, specific themes were chosen for in-depth analysis [i.e. selective coding, 23].

The analysis was thus conducted using an inductive approach, where the material was interpreted without using a predestined theoretical framework. The theories used in the article were consulted after identifying central themes in the material.

\section{Results}

The participants in the study had both positive and negative experiences of cooperating in the context of CAs. Generally, the positive experiences were related to evolving contacts across organizational borders and the possibility of developing new interorganizational work forms. The negative experiences were related to a perceived mismatch between cooperative work and sickness insurance regulations, and to problems related to the implementation of new work forms.

\section{Cooperation promotes coherence and communication}

Through the CAs, many different interorganizational work forms have been started to facilitate return-to-work or labour market reintegration for people who are considered difficult to manage within the organizations' regular practice. Examples are interdisciplinary 
rehabilitation teams and coordinators that facilitate joint planning of rehabilitation and returnto-work, as well as promoting a coherent message to the person on sick leave.

Rehabilitation coordinator, group 1: The good thing about the rehabilitation team is that we have a common structure so that the patient knows: this is what everybody thinks. You can't hedge in any way, or go to someone else, like it's been [before].

Cooperative teams were experienced as leading to informal personal networks that were used not only for the cases that the teams managed, but also in a more general sense. The contacts made through teams were used as entry tickets into other authorities and organizations, and to improve the rehabilitation process for the individual. Cooperation across organizational borders thus seems to have increased the participants' confidence in making contact with professionals in other organizations, something they previously were hesitant to do. Further, cooperation contributed to better understanding of shared concepts. An example is the concept of work ability, which is central in determining eligibility for sickness benefits. An enhanced understanding of other professionals' interpretations of this concept may contribute to improving the quality in work ability assessments.

\section{Contradictory tendencies: cooperative discretion and governance}

Several participants, representatives from healthcare and social services in particular, reported difficulties in applying cooperative work in rehabilitation issues because of an increasingly strict bureaucratic sickness insurance system. The recently legislated time schedule for returnto-work and labour market reintegration was mentioned as hindering the tailorization of rehabilitation, since it involves little flexibility. A general impression from the discussions was that sickness insurance regulations were perceived as contradicting cooperative work and 
vice versa: work forms initiated by the CAs more often contradicted regulations than acclaimed them.

Social welfare official, group 1: It doesn't matter how focused I am on finding solutions, because I can't turn the Social Insurance Agency around, saying I want more than twelve weeks. I try to put forward arguments, but it doesn't help. The paragraph says that this is what people should comply with. So what can I do?

The participants claimed to use the cooperative structures formally as well as informally to promote a good rehabilitation process, which implies a certain amount of professional discretion in planning this process in order to tailor it to individual needs. Here, the participants noted how the cooperative structures had been helpful, while at the same time contradicted by the regulations in sickness insurance. It was thus not possible to use the discretion offered through cooperative work forms because of the increased governance of the Social Insurance Agency's officials. In the end, the sickness insurance regulations made it difficult to be creative in finding solutions to fit individual needs, and made local knowledge of personal histories obsolete.

Social welfare official, group 2: I think there's a lot of local competence. There's so much knowledge here, we have to be able to believe in ourselves. And these people, the patients or the people who are insured, are known in healthcare. If only we could fix this here, at home, so to speak...

This plea by the municipal representative was quickly countered by the Social Insurance Agency official, who referred to a national control system for reviewing officials' decisions, which illustrates how officials in state authorities, through their references to national guidelines, may inhibit the use of local knowledge. 
The participants reported that several cooperative work forms initiated through CAs had been withdrawn. The two groups in the study had different experiences of this; the first group expressed much more disappointment with the development of the CA than the second group did. Since the two groups represent two different CAs, the differences can reasonably be attributed to the strategies chosen by the two CAs for developing cooperation.

The strategy of the first group's CA was based on allowing a multitude of cooperative work forms to start, followed by evaluation and implementation in regular practice if they were successful. However, after a few years, several cooperative work forms had been discontinued despite positive evaluations, which made the participants feel disappointed and frustrated. The participants expressed that the cooperation had enabled them to break organizational barriers and find new ways of working, and that all of a sudden the structure that delivered this was being withdrawn.

Rehabilitation coordinator, group 1: What I think is so sad is that we've torn down all of these walls in our organizations, and now they're being built up again. The Coordination Association goes in and starts projects, and then they say 'now we're shutting this down, now you own the problem', and the walls come right back up again. [...] And there's an evaluation that shows very good results, but it gets axed anyway because the organizations - the Employment Service, the Social Insurance Agency, the healthcare services, the municipalities - don't want to pay. So why should we work with this at all? Sometimes I think like that. And now there might be yet another new project starting.

The main reason for cancelling projects, as the participants experienced it, was that the participating organizations were not willing to take over the cost of the project when the CA withdrew the joint financing. This criticism was specifically aimed at the state authorities, who were perceived as unwilling to contribute to anything that was not their core responsibility. Hence, the gains from cooperative projects were lost because of financial 
priorities. There seemed to be a weariness among the participants of how especially the state authorities handled these issues. The Public Employment Service was seen as an organization that never contributed more than they had to; it was perceived that their self-interest hindered the other actors from continuing with the common work.

Rehabilitation coordinator, group 1: The Employment Service was involved in this [a team], but did they decide that it wasn't valuable, or what?

Social welfare official: No, they didn't have time.

Employment service official: They wanted the resources to be returned to the core business. [...]

Rehabilitation coordinator: All projects which have to bear their own costs are shut down by the Employment Service.

The strategy of the second group's CA was to initiate a central cooperation team, financed on a long-term basis by the participating organizations. In this group, the participants did not express any criticism of the development of the team; instead, they were positive regarding the potential of such cooperation for people with complex needs. The managers were also perceived as being more commited to continuing their contributions to the cooperation team on a long-term basis.

These results indicate that the local adaptation of the legislation that governs the CAs was different. The coordinators in the two CAs used different strategies for engaging managers and for setting up cooperative work between the participating organizations. Thus, there was a certain amount of discretion in the coordinator role, which influenced the development of the cooperation. 


\section{Discussion}

Two main obstacles to cooperative work have been identified: inflexible time limits in sickness insurance regulations, and implementation difficulties. Both these obstacles are related to difficulties for state authorities in adapting their practice to local conditions. The limited flexibility in the system makes it difficult not only for officials to tailor rehabilitation to individual needs, but also for managers to implement new work forms into regular practice.

\section{Promoting and preventing discretion}

The emerging network of officials from different rehabilitation actors has led to improved interorganizational communication, which is likely to reduce the risk of the "broken telephone" scenario, where single events of miscommunication add up to the point where cooperation breaks down [24]. However, this cooperation is dependent on a level of professional discretion in adapting rehabilitation to individual needs, which is difficult with increasingly inflexible sickness regulations. The participants in the study emphasize how the representatives from state authorities are increasingly governed by national policies and that they believe their level of discretion is decreasing. In addition, although representatives from local authorities generally seem to have a higher level of discretion in their work, they have to adapt to the current policies of the Social Insurance Agency, because this authority plays a central role in the rehabilitation process. This implies that the decreasing level of discretion in the Social Insurance Agency affects the entire system.

According to Lipsky, discretion is necessary for officials in delivering policy decisions to clients, and involves a balance between meeting people as individuals and treating them in a bureaucratic way [25]. Thus, in the end, policy is decided by officials at street level rather than by managers. Officials' work takes place within a multitude of rules and regulations, 
which according to Lipsky may actually be understood as promoting discretion: 'In most public welfare departments, regulations are encyclopedic, yet at the same time, they are constantly being changed. With such rules adherence to anything but the most basic and fundamental precepts of eligibility cannot be expected' [25, p. 14]. Following Lipsky, several studies have focused on the development of discretion in various social services. In the literature, two lines of arguments may be traced: one in favour of the continuation of discretion and the other for its curtailment [26]. In the curtailment literature, references are often made to the increase of managerialism, and the argument for curtailment relies on an assumption that increased steering also implies increased compliance. As Evans and Harris have noted [26], the empirical basis for this conclusion is weak. However, the results of this study indicate that increased managerial steering has decreased the discretion of the officials.

The participants in this study experience that cooperative work forms have provided greater scope for adapting policies to individual needs. However, increased governance from state authorities contradicts such a development, in that discretion is perceived as curtailed rather than promoted. In the end, the participants experienced this as a tug-of-war between themselves and the management's increasingly strict application of national regulations. These two forces affect the level of discretion in practice: officials are given opportunities through cooperative work forms that are withdrawn through governance. The results also suggest that the strategy for cooperative work chosen by local authorities influences how these forces will be balanced.

Another finding is that although there generally seem to be a more trust-based cooperation at the practical level than at the managerial level [cf. 8], the CAs differ in how well they manage to deal with the problems of commitment and low interorganizational trust. One CA has managed to involve the participating organizations in a long-term commitment, while the other has had problems maintaining contributions from the organizations. Thus, the strategy 
for cooperation seems to matter when balancing self-interests and preventing non-cooperative behaviour. The findings of the study suggest that short-term projects as a strategy for change should be used with caution, since they involve a risk that commitment ends with the closure of the project.

\section{Methodological considerations}

This study was explorative and open-ended, which allowed for an inductive analysis of professional experiences of interorganizational cooperation. The method used (continuous meetings with two interprofessional groups) made it possible to observe how representatives from different professions interact with regard to the effects of cooperation initiatives on practice and how the discussions evolved over time. Using a pedagogical method helped the participants to structure the meetings to focus on topics they observed as relevant for their situation.

Qualitative studies do not aim for generalization in a statistical sense; rather, the aim is to provide transferable data. The results of this study cannot be interpreted as generally reflecting the experience and attitudes of the organizations studied. However, there is no reason to assume that the results from this study are unique to its participants; they represent authorities and public organizations, and the issues discussed (such as interorganizational cooperation and the relationship between managers and staff) are widespread in a Swedish and an international context. The results from this study may thus be transferable to other similar contexts. However, as the discussion might have underlined the limited external validity due to considerable systems differences from one country to another, it points at the need to repeat this kind of research in other countries to discover the complexities of the cooperation among systems in this field. 
The trustworthiness of a qualitative study depends on four criteria: credibility, transferability, dependability, and confirmability [27]. Credibility can be understood as whether the reported findings from a study represent a credible conceptualization of the material; transferability is related to whether the results may be applicable to other contexts or projects; dependability is concerned with the overall quality of the research process from data collection to analysis; and confirmability is how well a study's findings are supported by the data collected.

The results from the study have been reported back to the participants through a seminar with participants from both groups, which is a way of elucidating the credibility and the confirmability of the findings. The dependability of the study is strengthened by continuous discussions about the material among the co-authors and with colleagues in seminars and informal discussions.

\section{Conclusions}

Although interorganizational cooperation in rehabilitation is generally perceived as promoting coherence and communication, there are several contradictory factors in the implementation of such work forms. The Swedish sickness insurance system has developed toward increasing regulation, for instance through a legislated time frame for return-to-work and labour market reintegration, which makes the system less flexible. While interorganizational cooperation promotes professional discretion and tailored solutions, the insurance system contradicts such ambitions through increased governance. Ultimately, the contradictory tendencies of cooperative initiatives and the stricter governance of sickness insurance regulations are political matters. If political attempts to promote interorganizational cooperation are to 
succeed, the increasing sectorization that results from strict governance of sickness insurance regulations needs to be targeted on a system level.

The different development of the two CAs in this study (where one has been able to attain sustainable cooperation and the other has not) shows the importance of local strategies for maintaining the positive effects of cooperation. Financial support can provide a starting point for cooperation, but it is not enough to ensure sustainability. Thus, it is important that longterm perspectives are taken into account when forming a cooperative structure, in order to make cooperation sustainable, and to prevent the development of distrust under the influence of vested interests.

\section{Declaration of interest}

The authors report no conflicts of interest. The authors alone are responsible for the content and writing of the paper.

\section{Acknowledgements}

The authors wish to thank the coordinators in the two CAs who helped in recruiting the participants for this study, and Ellen MacEachen for providing valuable comments on the paper. 


\section{References}

1. Brunarski D, Shaw L, Doupe L. Moving toward virtual interdisciplinary teams and a multistakeholder approach in community-based return-to-work care. Work. 2008;30(3):329-36.

2. Franche R-L, Baril R, Shaw W, Nicholas M, Loisel P. Workplace-Based Return-to-Work Interventions: Optimizing the Role of Stakeholders in Implementation and Research. Journal of Occupational Rehabilitation. 2005;15(4):525-42.

3. Friesen MN, Yassi A, Cooper J. Return-to-work: The importance of human interactions and organizational structures. Work. 2000;17(1):11-22.

4. Loisel P, Durand M-J, Berthelette D, Vézina N, Baril R, Gagnon D, et al. Disability Prevention: New Paradigm for the Management of Occupational Back Pain. Disease Management and Health Outcomes. 2001;9(7):351-60.

5. Loisel P, José-Durand M, Baril R, Gervais J, Falardeau M. Interorganizational Collaboration in Occupational Rehabilitation: Perceptions of an Interdisciplinary Rehabilitation Team. Journal of Occupational Rehabilitation. 2005;15(4):581-90.

6. MacEachen E, Clarke J, Franche R-L. Systematic review of the qualitative literature on return to work after injury. Scandinavian Journal of Work, Environment and Health. 2006;32(4):257-69.

7. Ståhl C, Svensson T, Petersson G, Ekberg K. The Work Ability Divide: Holistic and Reductionistic Approaches in Swedish Interdisciplinary Rehabilitation Teams. Journal of Occupational Rehabilitation. 2009;19(3):264-73.

8. Ståhl C, Svensson T, Petersson G, Ekberg K. A Matter of Trust? A Study of Coordination of Swedish Stakeholders in Return-to-Work. Journal of Occupational Rehabilitation. 2010;20(3):299-310.

9. Loisel P, Buchbinder R, Hazard R, Keller R, Scheel I, Tulder Mv, et al. Prevention of Work Disability Due to Musculoskeletal Disorders: The Challenge of Implementing Evidence. Journal of Occupational Rehabilitation. 2005;15(4):507-24.

10. Gardner BT, Pransky G, Shaw WS, Hong QN, Loisel P. Researcher perspectives on competencies of return-to-work coordinators Disability and Rehabilitation 2010;32(1):72-78. 11. Pransky G, Shaw WS, Loisel P, Hong QN, Désorcy B. Development and validation of competencies for return to work coordinators Journal of Occupational Rehabilitation. 2010;20(1):41-8.

12. Shaw W, Hong Q-n, Pransky G, Loisel P. A literature review describing the role of returnto-work coordinators in trial programs and interventions designed to prevent workplace disability Journal of Occupational Rehabilitation. 2008;18(1):2-15.

13. Jakobsson B, Bergroth A, Schüldt K, Ekholm J. Do systematic multiprofessional rehabilitation group meetings improve efficiency in vocational rehabilitation? Work. 2005;24:279-90.

14. Prins R. Integrated Services in Rehabilitation - on Coordination of Organization and Financing: Synthesis Report: European Commission2006.

15. Prins R. Integrated Services in Rehabilitation - on Coordination of Organisation and Financing: Discussion Paper: European Commission2006.

16. Sandström U, Axelsson R, Lundborg CS. Inter-organisational integration for rehabilitation in Sweden - variation in views on long-term goals. International Journal of Integrated Care. 2004;4:1-11.

17. Wihlman U, Lundborg CS, Axelsson R. Barriers of inter-organisational integration in vocational rehabilitation. International Journal of Integrated Care. 2008;8:1-12.

18. Patton MQ. Qualitative research and evaluation methods. 3 ed. London: Sage; 2002. 
19. Downey P, Waters M. Developing the primary healthcare team as a learning organisation: A new model using problem-based learning. Education for Primary Care. 2005; 16(3):301-7. 20. Lohman MC. Cultivating Problem-Solving Skills Through Problem-Based Approaches to Professional Development. Human Resource Development Quarterly. 2002;13(3):243-61.

21. Yeo RK. (Re)viewing problem-based learning: An exploratory study on the perceptions of its applicability to the workplace. Journal of Managerial Psychology. 2007;22(4):369-91.

22. Nielsen KA, Svensson L, editors. Action and Interactive Research: Beyond practice and theory. Maastricht: Shaker Publishing; 2006.

23. Neuman WL. Social Research Methods: Qualitative and Quantitative Approaches.

Boston: Pearson; 2006.

24. MacEachen E, Kosny A, Ferrier S, Chamber L. The "Toxic Dose" of System Problems: Why Some Injured Workers Don't Return to Work as Expected. Journal of Occupational Rehabilitation. 2010.

25. Lipsky M. Street-Level Bureaucracy: Dilemmas of the Individual in Public Services. New York: Russell Sage Foundation; 1980.

26. Evans T, Harris J. Street-Level Bureaucracy, Social Work and the (Exaggerated) Death of Discretion. British Journal of Social Work. 2004;34(6):871-95.

27. Lincoln Y, Guba E. Naturalistic inquiry. Newbury Park: Sage; 1985. 
Table 1: Actors and their responsibilities in rehabilitation and return-to-work in Sweden.

\begin{tabular}{|l|l|}
\hline Actor & Responsibility \\
\hline Employers & $\begin{array}{l}\text { Payment of sick pay during first 2 weeks of sick leave, workplace } \\
\text { rehabilitation and work accommodation }\end{array}$ \\
\hline Social Insurance Agency & $\begin{array}{l}\text { Payment of sickness benefits for up to 1 year, assessment of work } \\
\text { ability, coordination of the RTW process }\end{array}$ \\
\hline Public Employment Service & $\begin{array}{l}\text { Vocational rehabilitation after } 6 \text { months of sick leave, gatekeeper to } \\
\text { unemployment benefits }\end{array}$ \\
\hline Healthcare services & $\begin{array}{l}\text { Assessment of functional ability, gatekeeper to sickness benefits, } \\
\text { medical rehabilitation }\end{array}$ \\
\hline Municipalities & Social rehabilitation, social allowances \\
\hline
\end{tabular}

Table 2. Organizational background of the participants

\begin{tabular}{|l|l|}
\hline Group 1 & Group 2 \\
\hline Social Insurance Agency official & Social Insurance Agency official \\
\hline Public Employment Service official & Social Insurance official/cooperation team \\
\hline Occupational therapist, primary healthcare & Public Employment Service official \\
\hline Coordinator, primary healthcare & Coordinator, primary healthcare \\
\hline Psychiatry & Coordinator, primary healthcare \\
\hline Social welfare official & Social welfare official/cooperation team \\
\hline Municipal rehabilitation service & \\
\hline Municipal human resource manager & \\
\hline
\end{tabular}

